\title{
ART PEDAGOGICS IN COMPUTER GRAPHICS
}

\author{
Zhanar Nebesayeva \\ Kazakh National Pedagogical University named after Abay, Kazakhstan \\ Svetlana Koneva \\ Kazakh National Pedagogical University named after Abay, Kazakhstan
}

\section{Medeubek Tanirbergenov}

Southern Kazakhstan State Pedagogical Institute, Kazakhstan

\begin{abstract}
This article discusses the use of information technology, namely computer graphics. The possibility of using art pedagogics activities in computer graphics. From the perspective of the conceptual field students. Influence of processes unfolding in the information, spiritual levels, exacerbate the problem of improving the education system in accordance with the challenges of the time. In the context of the transformation of Kazakh school informatization of education is increasing scientific and practical need to find efficient models, innovative forms and methods of construction of educational pro $\neg$ tsessa. Providing favorable conditions for personal self-determination and human professio $\neg$ nalnogo. As well as substantial characteristics of the concepts of ,artpedagogika” in the context of the problems solved by the visual arts. The place and importance of art in education of the younger generation.
\end{abstract}

Keywords: art pedagogics, computer graphics, information technologies, specialty, graphic culture, art education.

\section{Введение \\ Introduction}

Образование должно помогатьлюдям становиться помощниками самим себе» - говорил И.Г. Песталоцци. Это высказывание отражается в тексте Послания Президента Республики Казахстан народу республики «Нурлы жол - путь в будущее», особое внимание обращено к молодежи. «Я всегда говорю: молодежь - опора нашего будущего, «Нурлы жол - Путь в будущее» - вот где можно приложить усилия, развернуться нашей креативной, динамичной молодежи!» [1]- Государство открыло перед новым поколением все двери и все пути!

Действительно, для полнокровной жизни молодых людей создаются все условия. Им есть где реализовать себя, свои знания и способности.

Глобальные процессы, разворачивающиеся на социальноэкономическом, информационном, духовном уровне в масштабах планеты, обостряют проблему совершенствования системы образования в соответствии с вызовами времени. В условиях преобразования казахстанской школы возрастает научно-практическая необходимость поиска эффективных моделей, инновационных форм и методов построения 
образовательного процесса, обеспечивающего благоприятные условия для личностного и профессионального самоопределения человека.

В нашем исследовании рассматриваются проблемы использования средств компьютерной графики не посредственно с артпедагогикой в ВУЗе. Возможности использования артпедагогической деятельности в компьютерной графике. В ракурсе понятийного поля студентов. Влияние процессов, разворачивающиеся на информационном, духовном уровнях, обостряют проблему совершенствования системы образования в соответствии с вызовами времени. В условиях преобразования казахстанской школы информатизации образования возрастает научнопрактическая необходимость поиска эффективных моделей, инновационных форм и методов построения образовательного процесса. Обеспечивающего благоприятные условия для личностного и профессионального самоопределения человека. А также содержательные характеристики понятий «артпедагогика» в контексте задач, решаемых изобразительным искусством. Место и значение искусства в воспитании подрастающего поколения.

В связи с требованиями нынешнего времени, практически все люди изучают элементы компьютерной графики независимо от специальности. Соответственно следует формировать графическую культуру у каждого человека. Под графической культурой в узком смысле мы понимаем умение обрабатывать, передавать, создавать графические объекты с помощью технических средств. Понятие графическая культура шире, чем мы его понимаем, т.к. это еще и умение рисовать, строить и читать графические чертежи и др.

Таким образом, обладать графической культурой в полном смысле значит, владеть графической культурой, навыками решения задач по теме, приемами управления растровыми и векторными объектами, приемами работы в растровых и векторных редакторах, техникой верстки печатной продукции в настольной издательской системе, навыками разработки анимации, навыками программирования графических объектов и многое другое.

Подготовка в области компьютерной графики в Казахстане начинается еще на ступени среднего образования. Программы общеобразовательной подготовки для системы среднего образования включают изучение таких тем в области компьютерной графики, как: «Графический редактор Paint» (4 класc), «Представление графической информации» (7 класс), «Разработка презентаций» (10 класс), «Графический редактор AdobePhotoShop» (11 класc), «Графический редактор CorelDraw» (11 класc), «Издательское дело в AdobePageMaker» (11 класс).

К сожалению, не во всех школах эта подготовка осуществляет полно и качественно. Курс «Информатика», который изучается уже в системе 
вузовского образования ориентирован на ликвидацию пробелов довузовской подготовки.

Содержание вузовского курса «Информатика» в последние годы в Республике Казахстан определяется для всех специальностей однозначно, без учета специфики будущего специалиста. Согласно существующим и новым стандартам образования в курсе информатики уделяется особое внимание рассмотрению графических редакторов, их классификации. Новые стандарты обошли стороной такие темы, ставшие «фундаментальными», как «Разработка презентаций», «Настольные издательские системы».

В России ситуация немного другая. В содержании курса информатики изучение компьютерной графики представлено двумя основными разделами: компьютерная графика и программные средства ее создания, презентации и программные средства из создания.

Данные разделы позволяют сформировать у студентов не только ключевые компетенции, но и сформировать специальные компетенции в области компьютерной графики. Авторы российских программ выделяют незначительное количество времени на изучение графических редакторов: на изучение каждого раздела выделено 24 часа, из них только 4 часа аудиторных, а остальное время отведено на самостоятельную работу студента.

Отметим, что корректировка содержания обучения разделам компьютерной графики в курсе информатики для студентов с учетом специальностей возможна следующим образом: наполнение презентации соответственным содержанием, обработка готовых изображений, подготовка и создание изображений, создание готовой печатной продукции с учетом будущей профессиональной сферы.

Существующий курс информатики позволяет сформировать ключевые компетенции: базовые понятия графической культуры, умения использовать графические редакторы, навыки разработки презентации и программные средства ее создания. Но, дисциплина информатика не позволяет сформировать следующие знания: теоретические основы компьютерной графики, отличие между видами графики, основные цветовые модели, понятие и назначение графических редакторов, их классификацию, понятие настольной издательской системы, основные понятия Web-графики, методы передачи графической информации по сети, технологии разработки анимационных изображений, Flash-технологию, алгоритмы растровой графики, алгоритмы векторной графики, алгоритмы трехмерной графики, основы геометрического моделирования. Компьютерная графика призвана ликвидировать эти пробелы.

Целью дисциплины «Компьютерная графика» является формирование у студентов компетенции применения методов и средств компьютерной 
графики в своей будущей профессиональной деятельности в условиях информатизации образования.

Необходимым для осуществления этой цели являлся минимальный комплект требуемых лицензионных программ последних доступных версий, шрифтов и плагинов к ним: - Adobe Photoshop, - Adobe Illustrator, Adobe Photoshop Lightroom, - Corel Painter. Не маловажную роль играла самостоятельная (домашняя) работа, подготовка студентов к просмотрам и выставкам в современных условиях связанных с информационными дистанционными технологиями. В данном случае используются ресурсы сети интернет: электронная почта и программы, позволяющие общаться и обмениваться информацией в онлайн режимах (Mail.ru Агент, Skype, Вконтакте, Одноклассники, Facebook и т.п.)

Суть формирующего исследования заключалась во введении в процесс обучения вариативных теоретических и практических блоков, выстраивании процесса обучения в контрольных и экспериментальных группах на различных принципах и подходах. Экспериментальные группы обучались по предлагаемой экспериментальной методике, суть которой заключается в том, что задания по компьютерной графике были систематизированы по уровню сложности и требуемым знаниям, умениям и навыкам. По направлению «дизайн» в графическом дизайне был сделан акцент на предметную, портретную, событийную, репортажную, социальную и жанровую фотографию, а также съемку животных и растений для специализации «графический дизайн: дизайн рекламы», а также акцент на ретушь, предпечатную обработку, работу с цифровым изображением и коллажирование для специализации «графический дизайн: дизайн полиграфии» и специализации «графический дизайн: Web-дизайн».

Для проверки рабочей гипотезы по активизации творческой деятельности студентов-дизайнеров на базе института искусства, культуры испорта Каз НПУ им. Абая был проведен формирующий этап экспериментальной работы. Всего в эксперименте участвовало 33 студента. Стартовый уровень и количество человек в контрольных и экспериментальных группах были равными. Суть формирующего эксперимента заключалась во введении в процесс обучения вариативных теоретических и практических блоков, выстраивании процесса обучения в контрольных и экспериментальных группах на различных принципах и подходах. Экспериментальные группы обучались по предлагаемой экспериментальной методике, контрольные группы обучались по традиционной методике. Группу заданий по компьютерной графике в экспериментальной группе мы систематизировали по уровню сложности и требуемым знаниям, умениям и навыкам для объективности полученных экспериментальных результатов. Формирующий эксперимент включал следующие задания для обеих групп: черно-белая фотография; 
тематическая, предметная съемка и натюрморт; съемка природы и животного мира, пейзаж; съемка архитектуры и городского пейзажа.

Примеры учебно-методических заданий для самостоятельной работы обучающихся:

1. Фотография, фотоискусство и фотографика в рамках современной визуальной культуры. Освоение техники фотосьемки. Фотография: история, эстетика, культура. Аналоговая и цифровая фотография, использование пользовательских настроек фототехники, освоение фотооборудования, использование фототехники в различных условиях освещения, основы работы с дополнительными источниками освещения. Самостоятельная работа: чтение литературы, практическое освоение, техники съѐмки. Форма отчетности: составление конспекта и серия фотографий.

2. История фотоискусства, фотографики и эволюция фотографических технологий. Мировая и отечественная история фотографики и эволюция фотографических технологий. Использование различных способов получения фотоизображения, освоение принципов работы с аналоговой и цифровой фотографией. Самостоятельная работа: чтение литературы, практическое освоение приемов, получение фотоизображения. Форма отчетности: составление конспекта и серия фотографий.

3. Задачи и средства фотографики. Работа в графических редакторах. Освоение принципов работы в пакетах программ Adobe Photoshop, Corel Draw, Corel Painter, Adobe Lightroom и использование плагинов. Самостоятельная работа: чтение литературы, практическое освоение приемов работы в графических редакторах. Форма отчетности: составление конспекта и серия фотографий.

Этапы формирования:

1. Работа на учебных занятиях - практические занятия на очном отделении

2. Самостоятельная работа - при выполнении домашних заданий: выполнение эскизов, кроки и клаузур к фотопроекту; - изучение специальной рекомендованной литературы; - изучение графических редакторов; - выполнение допечатной подготовки фотопроекта.

Специфика формирования и оценки знаний, умений, навыков по искусству художественной фотографии заключается в том, что для полноценного изучения художественной фотографии ввиду малого объема как лекционных, так и практических аудиторных часов существует необходимость интегративного подхода в изучении тем, связанных с 
фотографикой и фотоискусством. Существующий объем часов дает возможность получить относительно поверхностные знания изучаемой дисциплины, мало способствует формированию компетентного специалиста-дизайнера. Для повышения эффективности учебного процесса возможно включение блока тем и заданий по фотографике, фотоискусству, компьютерной графике в дисциплины, связанные с проектированием в дизайне (т.е. в методику целесообразно вводить элементы проектной деятельности, а в проектной деятельности применять знания, умения и навыки художественной фотографии, компьютерной графики и фотоискусства).

В итоге студент должен был самостоятельно применить на практике метод «использования средств искусства». Как отмечают педагоги, «художественный анализ картины ... - моменты преподавания многих предметов [2]. Характерной чертой метода выступает неотделимость от чувства удовольствия, радостного подъема».

Коэффициенты сформированности с первого по четвертый курс отделения «Дизайн», направлений «Графический дизайн», «Дизайн костюма» в контрольных и экспериментальных группах рассчитаны в соответствии со следующей системой: уровень группы «низкий» по критерию соответствует коэффициенту в пределах от 1 до 2,5; уровень группы «средний» по критерию соответствует коэффициенту в пределах от 2,6 до 3; уровень группы «высокий» по критерию соответствует коэффициенту в пределах от 3,1 до 5 . Динамика формирования компетенций по различным критериям отражена на диаграммах (см. рисунки 1-2).

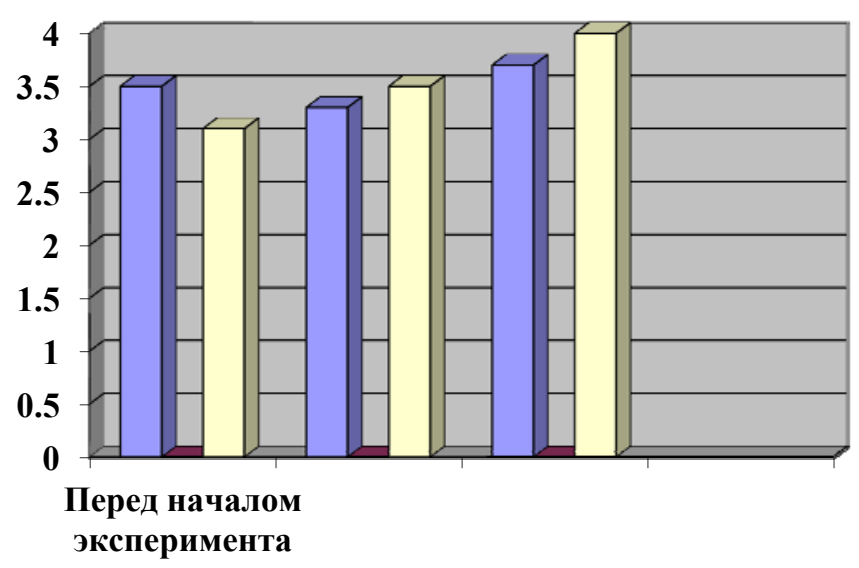

口Контрольные группы

口Экспериментальные группы

Рисунок 1. Динамика формирования компетенций по критерию «Обнаружение и постановка творческой задачи» в экспериментальных и контрольных группах 


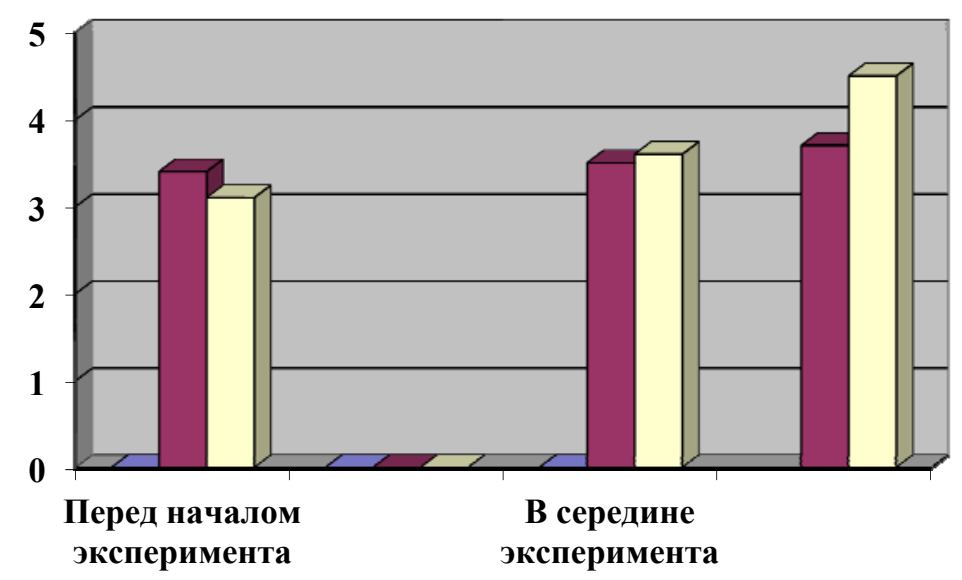

口контрольные группы

$\square \mathbf{0}$

口Экспериментальные группы

Рисунок 2. Динамика формирования компетенций по критерию «Оригинальность творческого решения» в экспериментальных и контрольных группах

Выводы по формирующему эксперименту: - У обучающихся по традиционной методике (контрольные группы) были выявлены сложности в развитии художественно-образного и проектного мышления в фотографии. Недостаточно эффективно шло освоение техники съемки. Также было выявлено недостаточное внимание в традиционных методах обучения современным приемам ретуши и работы с растровой графикой.

У обучающихся по экспериментальной методике (экспериментальные группы) было выявлено более успешное освоение заданий. Поскольку для оценки эффективности на коллегиальных просмотрах экспертными комиссиями кафедр мы использовали стобалльную систему оценивания, средние результаты эксперимента показали коэффициенты, которые при переводе в стобалльную систему оценивания равнялись 86 баллам в экспериментальных группах (коэффициент 4) и 71,2 баллам в контрольных группах (коэффициент 3,2). Результаты в экспериментальных группах таким образом, отличались на 14,8 баллов в сторону повышения, что может быть оценено как большая эффективность экспериментальной методики по сравнению с традиционной на 14,8\%. Длительность и вариативность проведения педагогического эксперимента позволяет судить об объективности и устойчивости полученных результатов.

По итогам исследования, на основе всестороннего анализа литературы по смежным тематикам, накопления педагогического и творческого опыта, а также опираясь на теоретические и практические результаты, мы сформулировали следующие выводы: Итогом работы было достижение поставленной цели - разработки, научного обоснования, экспериментальной проверки и отработки эффективной методики 


\section{SOCIETY. INTEGRATION. EDUCATION. Volume I}

обучения компьютерной графики с интеграцией артпедагогики в процессе обучения дизайнеров.

Экспериментально подтверждено предположение о том, что деятельность студентов средствами художественной фотографии в процессе обучения дизайнеров возможна при соблюдении следующих условий: исследовании научных трудов ведущих специалистов в области физиологии, психологии, теории и методики преподавания изобразительного искусства, искусствоведения, фотоискусства, высказываний и творческого опыта ведущих российских и зарубежных художников-педагогов и фотохудожников; использовании комплекса эффективных методов и подходов по развитию и раскрытию личностного потенциала студентов в разных категориях дисциплин, использовании компетентностного, интегративного, применении информационнокомпьютерных технологий, технических средств обучения и онлайн консультирования; использовании в процессе обучения дизайнеров учебных заданий с широким спектром межпредметных связей, включении элементов ряда дисциплин композиции, цветоведения и 94 колористики, использовании системы заданий и упражнений, демонстрирующих приемы достижения образной выразительности и реализации творческих возможностей художественной фотографии.

\section{Summary}

The study addressed the following tasks: the analysis of scientific and theoretical aspects of the creative activity of students and disclosed art pedagogic bases activation of creative activity; The possibilities of art photography in the activation of creative activity of students considering studying the expressive means of artistic photography, the study of modern means of expression of artistic photography and analysis of its direction; identified criteria for evaluating the creative activity of students in the class in artistic photography, tested the effectiveness of the experimental method of learning the art of art photography in the learning process design students; confirmed the objectivity of the results obtained through the implementation of key elements of the experimental teaching methods Art photography systems art pedagogic education and additional professional education.

\section{Литература \\ References}

Лемберг, Р.Г. (1958.). Методы обучения в школе. Алма-Ата.

Послание Президента Республики Казахстан Н. Назарбаева народу Казахстана. 11 ноября 2014 г. http://www.akorda.kz/ 